\title{
Performance Comparison of Symmetric and Offset Reflector Antennas Adaptively Illuminated by Novel Triple Mode Feedhorn
}

\author{
Satish K. Sharma and Mukund R. Thyagarajan \\ Antenna and Microwave Laboratory (AML), Department of Electrical and Computer Engineering, San Diego State University, \\ 5500 Campanile Drive, San Diego, CA 92182-1309, USA \\ Correspondence should be addressed to Satish K. Sharma, ssharma@mail.sdsu.edu
}

Received 19 June 2012; Revised 2 August 2012; Accepted 14 August 2012

Academic Editor: Ananda S. Mohan

Copyright ( $\odot 2012$ S. K. Sharma and M. R. Thyagarajan. This is an open access article distributed under the Creative Commons Attribution License, which permits unrestricted use, distribution, and reproduction in any medium, provided the original work is properly cited.

\begin{abstract}
Parabolic symmetric and offset reflector antennas adaptively illuminated using a novel triple-mode feedhorn $\left(\mathrm{TE}_{11}+\mathrm{TM}_{01}+\mathrm{TE}_{21}\right)$ with different mode combinations and impedance and radiation performances are presented. The combination of the radiating modes in a feedhorn with proper amplitude and fixed phase values helps in electronically pointing the main beam of the radiating patterns such as that obtained in a beam-steering antenna with limited beam-scan range. This type of radiation performance virtually creates a displaced phase center location for the feedhorn, which, consequently, adaptively illuminates the reflector antenna surface. Impedance-matching bandwidths are preserved for both reflector antennas similar to the case of feedhorn alone. The copolarization gain and peak cross-polarization levels are far better with the offset reflector antenna than the symmetric reflector antenna. Such reflector antennas find applications in ground moving target indicator (GMTI) and space based radars. The investigation results are solely computed using FEKO full-wave analysis tool.
\end{abstract}

\section{Introduction}

Reflector and feedhorn antenna assemblies have been widely used for various applications requiring high gain and narrow beamwidth radiation patterns such as satellite communications and radar applications [1]. A dual mode horn as a feed source was investigated for symmetric and offset reflector antennas in $[2,3]$ where $\mathrm{TE}_{11}$ and $\mathrm{TM}_{01}$ modes were excited to generate horizontal $\left(\mathrm{Phi}=0^{\circ}\right.$ ) plane multiple phase centers and consequently, reflector antenna radiation performance was presented. This antenna had a targeted application for the GMTI radar. Similarly, the $\mathrm{TE}_{11}$ and $\mathrm{TE}_{21}$ modes based horn was also investigated for a vertical $\left(\mathrm{Phi}=90^{\circ}\right)$ plane multiple phase centers in [4]. For a GMTI radar or spacebased radar kind applications, multiple beam pointing from a feedhorn is desired, where a specific feed pattern position refers to a specific phase center location. The resulting reflector antenna radiation patterns are then processed using digital signal processing techniques to predict moving target location, shape, size, and so forth. Further, in [5], the authors investigated a virtual reflector antenna performance by employing $\mathrm{TE}_{11}+\mathrm{TM}_{01}$ and $\mathrm{TE}_{11}+\mathrm{TE}_{21}$ modes as theoretical modes in a feed pattern.

To offer additional flexibility in adaptive illumination of the reflector surface, where feed pattern is scanning in $\pm \theta$ angle in both the $\mathrm{Phi}=0^{\circ}$ and $90^{\circ}$ planes, a triplemode feedhorn $\left(\mathrm{TE}_{11}+\mathrm{TM}_{01}+\mathrm{TE}_{21}\right)$ is employed as a source to the reflector surfaces. Consequently, reflector antenna impedance matching and radiation performance are investigated for both the symmetric and offset reflectors and a comparison is made when only two modes from the feedhorn are excited at a time. The triple-mode feedhorn operates in the frequency range of $7.47 \mathrm{GHz}$ to $8 \mathrm{GHz}$ and generates beam scanning performance by exciting the modes in proper amplitude and phase combinations which was preliminarily discussed in [6]. Some initial investigations on the reflector antenna performance with this feedhorn were presented in [7]. One of the aims is to achieve minimum $500 \mathrm{MHz}$ instantaneous frequency bandwidth when all the modes are impedance matched $\left(S_{\mathrm{ii}}=-10 \mathrm{~dB}\right)$. Additionally, reflector antenna gain should be minimum $34 \mathrm{dBi}$, although any higher gain is certainly better. Infact, by employing three 


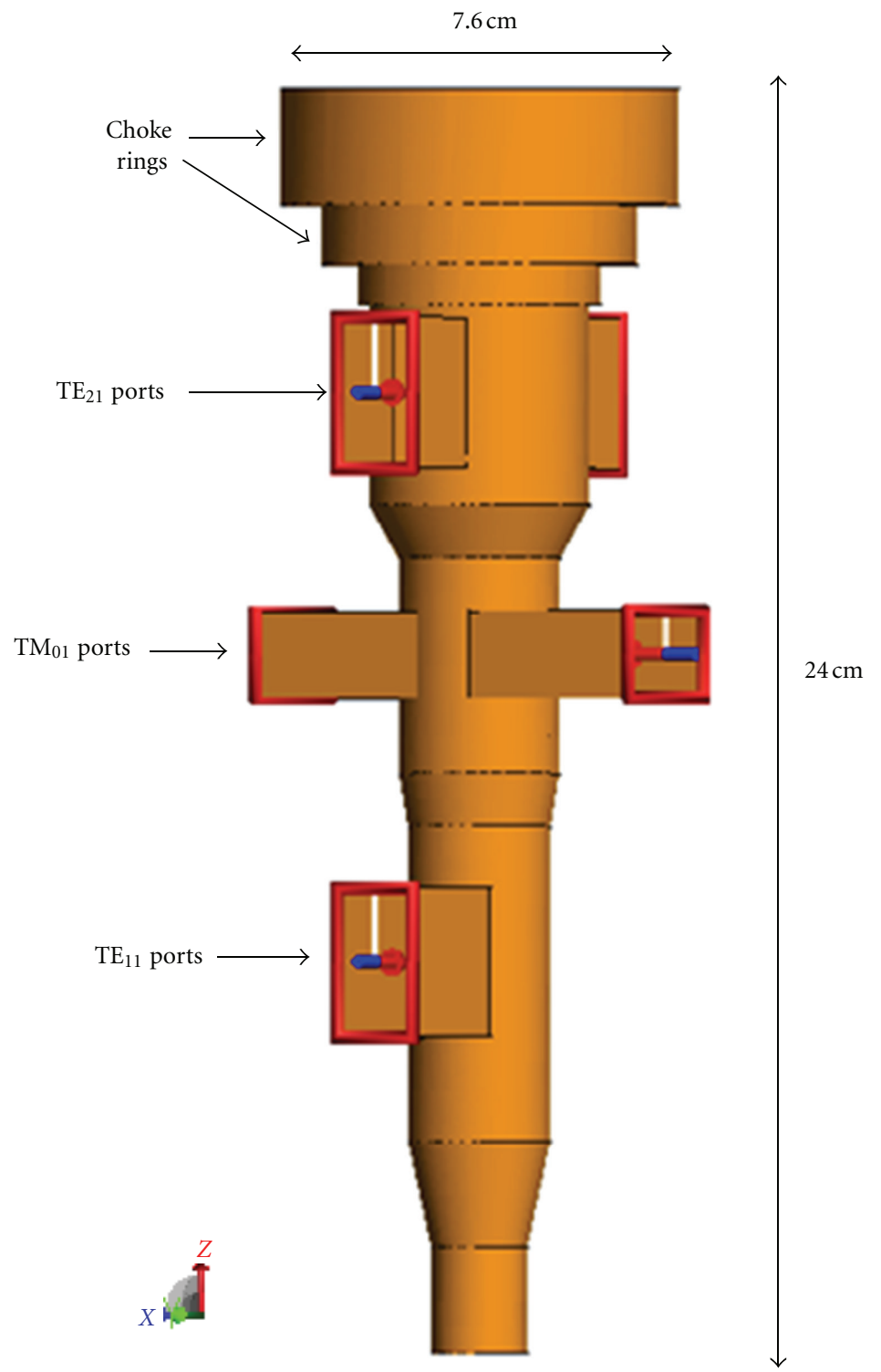

FIGURE 1: Geometry of the triple-mode feedhorn designed using CADFEKO.

modes in feed, we have been able to achieve gain around $37 \mathrm{dBi}$, which is $3 \mathrm{~dB}$ high. Additionally, the current feedhorn is capable of offering a horizontal or vertical or combination of both phase center positions which can give additional flexibility for applications such as the GMTI radar.

The simulation and analysis have been performed using EMSS's FEKO tool which is a Method-of-Moment (MOM) based Maxwell equation solver [8]. While method of moment (MOM) is used for feedhorn analysis, reflector antenna performance is computed using physical optics (PO) method using hybridization technique inbuilt with the FEKO.

\section{Triple-Mode Feedhorn Performance}

A novel triple-mode feedhorn designed earlier in [6] is reanalysed using FEKO. The feedhorn that excites the $\mathrm{TE}_{11}$,
$\mathrm{TM}_{01}$, and $\mathrm{TE}_{21}$, modes is analysed to understand its impedance and radiation performance as well as radiation performance when the modes are combined. The geometry of the feedhorn is as shown in Figure 1. The horn has two chokes at the aperture to maintain beamwidth required for illumination of the reflector. Three circular waveguides of selected radii: $1.34 \mathrm{~cm}, 1.53 \mathrm{~cm}$, and $2.1 \mathrm{~cm}$, respectively, are used to support the $\mathrm{TE}_{11}, \mathrm{TM}_{01}$, and $\mathrm{TE}_{21}$ modes. The diameters of the circular waveguides supporting above modes are selected in accordance to the Bessel function equations [9]. For exciting the $\mathrm{TM}_{01}$ and $\mathrm{TE}_{21}$ modes, two rectangular waveguides each are employed as shown in Figure 1 . The rectangular waveguides are oppositely placed in the $\mathrm{TE}_{21}$ mode than the $\mathrm{TM}_{01}$ mode. Further, while the $\mathrm{TE}_{11}$ mode is horizontally polarized, $\mathrm{TM}_{01}$ mode is vertically polarized. Similalrly, $\mathrm{TE}_{21}$ mode is horizontally polarized. The total length of the horn is $24 \mathrm{~cm}$ with an aperture diameter of $7.6 \mathrm{~cm}$. 
The reflection coefficient magnitudes for the triple-mode feedhorn (Figure 1) are shown in the Figure 2. For the $\mathrm{TE}_{11}$ mode, a matching bandwidth better than, $S_{11} \leq-10 \mathrm{~dB}$, is from $7.43 \mathrm{GHz}$ to $7.94 \mathrm{GHz}$ which is our main band of operation. It is observed that the reflection coefficient of the other ports, that is, $S_{22}, S_{33}$ exciting $\mathrm{TM}_{01}$ mode is from 7.46 to $8.34 \mathrm{GHz}$ and $S_{44}, S_{55}$ exciting the $\mathrm{TE}_{21}$ mode is from 7.3 to $8.05 \mathrm{GHz}$. The feedhorn's center frequency of operation is $7.73 \mathrm{GHz}$. The overall common bandwidth considering all the modes is from $7.43 \mathrm{GHz}$ to $7.94 \mathrm{GHz}$ which approximates to $510 \mathrm{MHz}$ and can meet the bandwidth requirements for several practical GMTI radar applications.

The Gain radiation patterns of the triple-mode feedhorn with the selected mode combination of $\mathrm{TE}_{11}(20 \%)+$ $\mathrm{TM}_{01}(40 \%)+\mathrm{TE}_{21}(40 \%)$ with $\pm 90^{\circ}$ fixed phase values are shown in Figures 3(a) and 3(b), respectively. The amount of power in respective modes is shown in percentage. The peak copolarization gain obtained is found to be $9.77 \mathrm{dBi}$. Peak cross-polarization level is also around $-4.1 \mathrm{~dB}$ from copolarization beam peak for either of the cases. The peak copolarization gain is found to occur at scan angle of $\theta=$ $\pm 18^{\circ}$ for the $\pm 90^{\circ}$ phase values. It can also be seen that as phase changes from $+90^{\circ}$ to $-90^{\circ}$, the direction of the beam peak changes from $+\theta$ to $-\theta$. Also both copolarization beam peaks are scanning in this case contrary to the $\mathrm{TE}_{11}+$ $\mathrm{TM}_{01}$ and $\mathrm{TE}_{11}+\mathrm{TE}_{21}$ mode combinations based radiation patterns where only one copolarization beam peak scans $[2,4]$. Beam scan angles can further be varied by varying the mode power contents as shown in Figure 4. It can be seen that as the $\mathrm{TE}_{11}$ mode power decreases, beam scan angle increases, however at the cost of gain drop. These adaptive feed patterns, controlled by amplitude contents with either $+90^{\circ}$ or $-90^{\circ}$ fixed phase values, when illuminate the reflector surface will have reflector patterns corresponding to different phase centers.

The beam scanning capability directly translates to the change is phase center location of the feedhorn as discussed in $[2,3]$, therefore we only show phase center for a selected power contents for the mode combination with the fixed phase values. Thus a study was performed to determine the phase center of this feedhorn with the mode combination of the $\mathrm{TE}_{11}(40 \%)+\mathrm{TM}_{01}(30 \%)+\mathrm{TE}_{21}(30 \%)$ with $+90^{\circ}$ and $-90^{\circ}$ fixed phase. In Figure 5, far field $E_{\text {Vertical }}$ and $E_{\text {Horizontal }}$ phase curves represent the $X Z$ and $Y Z$ cuts copolarizations parameter for the above mentioned mode combination with the selected power contents and phase value of $+90^{\circ}$. Similarly, phase curves of the $E_{\text {Vertical_1 }}$ and $E_{\text {Horizontal_1 }}$ represent the $X Z$ and $Y Z$ cuts copolarization parameter for the same mode behavior but with the $-90^{\circ}$ phase. These are as a result of several parametric simulations to determine this position and after extensive analysis, we determined its position to be at $X= \pm 7.6 \mathrm{~mm}$ and $Y=-2 \mathrm{~mm}$ which are shown in Figure 5. For the mode combination with phase of $+90^{\circ}$, we observe it at $X=-7.6 \mathrm{~mm}, Y=-2 \mathrm{~mm}$ and for the $-90^{\circ}$ case, we observe it to be at $X=+7.6 \mathrm{~mm}$, $Y=-2 \mathrm{~mm}$. The curves are flat in this region which is a requirement for determining the phase center. The displaced phase center position can similarly be found for different other mode combinations too; however, it is somewhat a trial

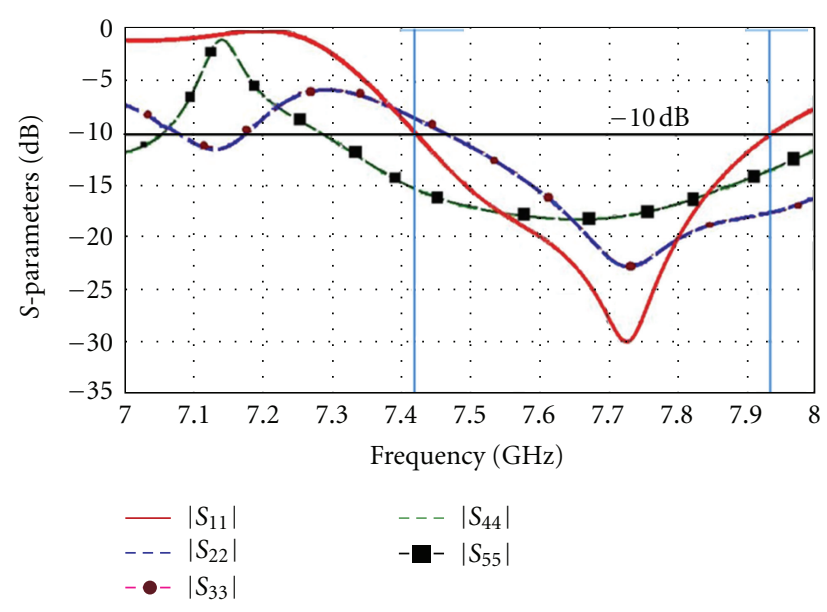

FIGURE 2: Reflection coefficient magnitudes for the $\mathrm{TE}_{11}, \mathrm{TM}_{01}$, and $\mathrm{TE}_{21}$ modes excited in the triple-mode feedhorn.

and error procedure which takes enormous effort to exactly point the phase center position, especially using a full wave analysis tool. Due to this reason and also that a detailed phase center study was shown in [2], hence is not included here. Additional triple-mode feedhorn performance results were discussed in [6], therefore are omitted here for the sake of brevity.

\section{Symmetric Reflector Antenna Performance with Triple-Mode Feedhorn}

A reflector antenna is basically a scattering surface which when properly illuminated by a feed source reflects the incident rays as a concentrated bundle of parallel rays or plane wave and consequently, resulting into high gain antenna performance depending upon the aperture area of the reflector surface [1]. The triple-mode feedhorn discussed in the previous section is used as a feed source to illuminate the surface of a symmetric parabolic reflector as shown in Figure 6. This reflector antenna is designed with $f / D$ ratio $=0.50$ and reflector diameter, $D=1.2$ meter. The full feed and reflector antenna model has been generated using EMSS's FEKO tool which is well recognized for analyzing problems relating to electrically large surfaces and uses different solution methods to solve the full antenna model. One of the advantages of this tool is that we not only compute radiation performance, but also impedance matching result is computed which basically considers the interaction of the feed with the reflector surface.

The reflection coefficient magnitudes for excited modes of the feedhorn, when illuminating the reflector surface are shown in Figure 7. This considers any interactions between the feed and reflector surface. It can be observed that matching bandwidth is preserved as obtained for the feedhorn alone (Figure 2). The common matching bandwidths, for all the modes, is from 7.48 to $7.97 \mathrm{GHz}$ with $S_{11}$ better than $-10 \mathrm{~dB}$ matching criteria. In the plot, the $S_{11}$ corresponds to the reflection coefficient of the $\mathrm{TE}_{11}$ mode, $S_{22}$ and $S_{33}$ 


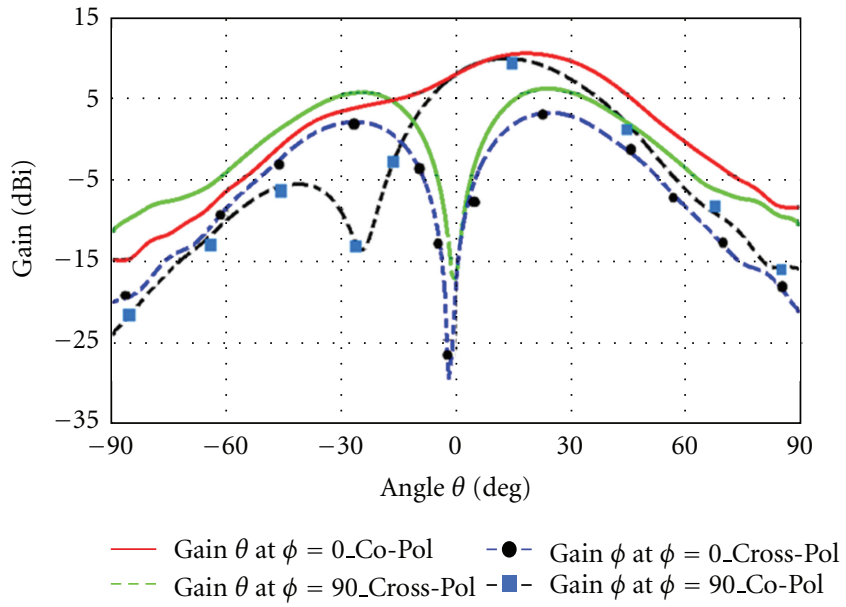

(a)

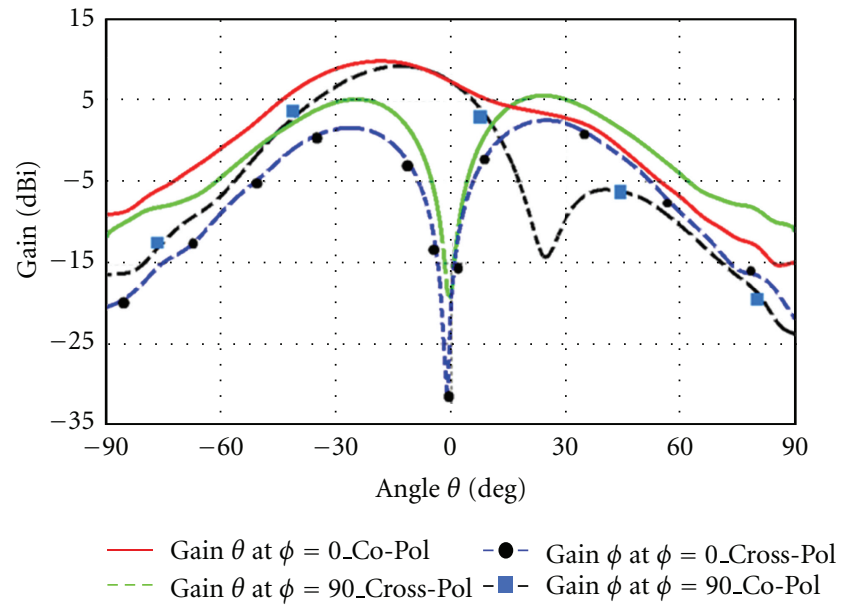

(b)

FIGURE 3: Gain radiation patterns of the triple-mode feedhorn with mode combination of $\mathrm{TE}_{11}(20 \%)+\mathrm{TM}_{01}(40 \%)+\mathrm{TE}_{21}(40 \%)$ at $7.73 \mathrm{GHz}$ for $(\mathrm{a})+90^{\circ}$ fixed phase, and (b) $-90^{\circ}$ fixed phase.

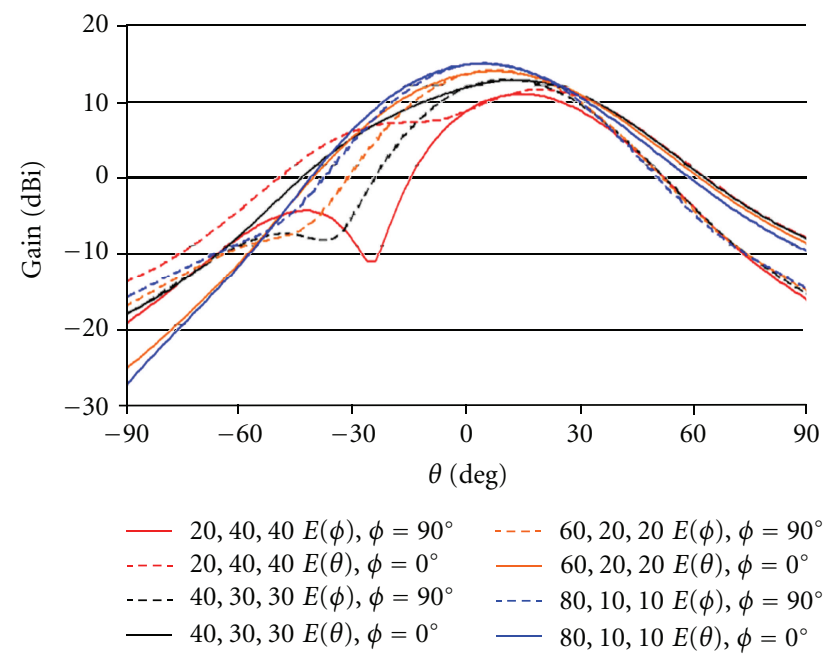

Figure 4: The triple-mode feedhorn copolarization gain patterns with variable amplitude contents in $\mathrm{TE}_{11}+\mathrm{TM}_{01}+\mathrm{TE}_{21}$ modes at $7.73 \mathrm{GHz}$ for $+90^{\circ}$ fixed phase. Power contents in modes are mentioned as percentage.

corresponds to the reflection coefficient of the $\mathrm{TM}_{01}$ mode, $S_{44}$ and $S_{55}$ corresponds to the reflection coefficient of the $\mathrm{TE}_{21}$ mode.

The reflector antenna radiation patterns are shown in Figures 8(a) and 8(b), when the feedhorn excites dual mode only with the equal mode power contents of the $\mathrm{TE}_{11}(50 \%)$ $+\mathrm{TM}_{01}(50 \%)$ but for $+90^{\circ}$ and $-90^{\circ}$ phase differences, respectively. We observe from Figures 8(a) and 8(b) that the peak gain values of $35.18 \mathrm{dBi}$ are occurring for Phi $=0^{\circ}$ cut palne at $+1.2^{\circ}$ and $-1.2^{\circ}$ for $+90^{\circ}$ and $-90^{\circ}$ phase differences, respectively. This beam squint is not an expectation because of the feed's scanned patterns or because of the phase center displacement rather it is computation

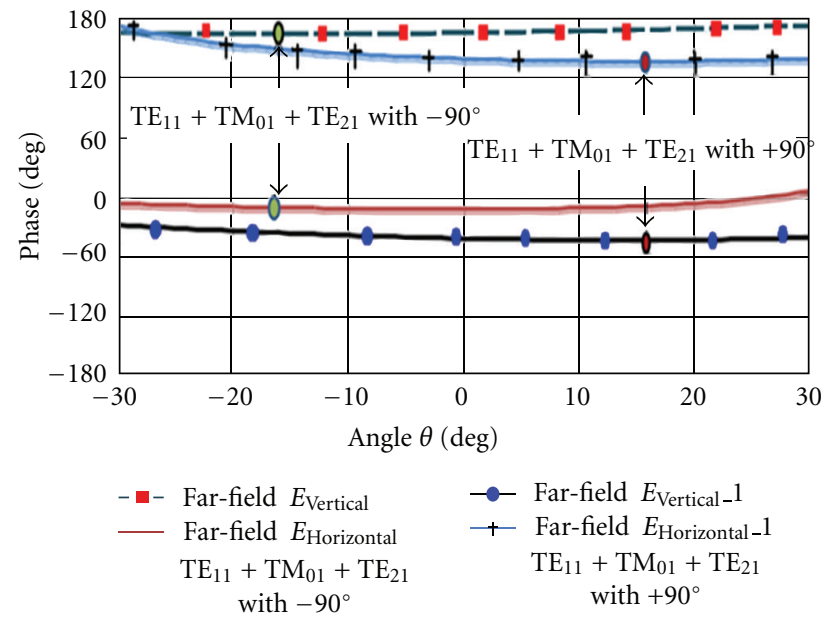

Figure 5: Phase distribution for the triple-mode feedhorn at $7.73 \mathrm{GHz}$.

error. The peak cross-polarization levels are quite high $-8.74 \mathrm{~dB}$ for the two mode excitations, which is attributed to the higher order mode radiation behavior. The peak crosspolarization curve is Gain $_{\text {theta }}$ at phi $=90^{\circ}$ cut plane.

Now, the reflector antenna radiation patterns for the feedhorn's dual mode combination of $\mathrm{TE}_{11}(50 \%)+$ $\mathrm{TE}_{21}(50 \%)$, which has equal mode power distribution with $+90^{\circ}$ and $-90^{\circ}$ phase differences, are shown in Figures 9(a) and 9(b), respectively. We observe from Figures 9(a) and 9(b) that, the peak gain values of $34.75 \mathrm{dBi}$ are occurring for Phi $=90^{\circ}$ cut plane at $+1.4^{\circ}$ and $-1.4^{\circ}$ for $+90^{\circ}$ and $-90^{\circ}$ phase differences, respectively. As mentioned earlier, the beam scan is not because of the feed's scanned patterns or because of the phase center displacement. The peak cross-polarization curve is now Gain phi $_{\text {at }} \mathrm{Phi}=0^{\circ}$ cut. The peak crosspolarization levels are still high $-11.75 \mathrm{~dB}$ for the two mode 


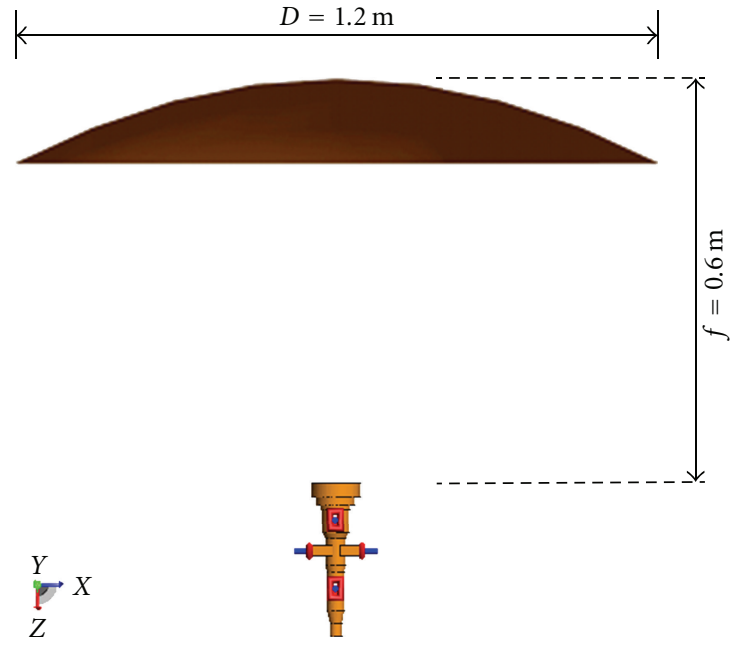

FIGURE 6: Feedhorn with a parabolic reflector antenna in symmetric configuration.

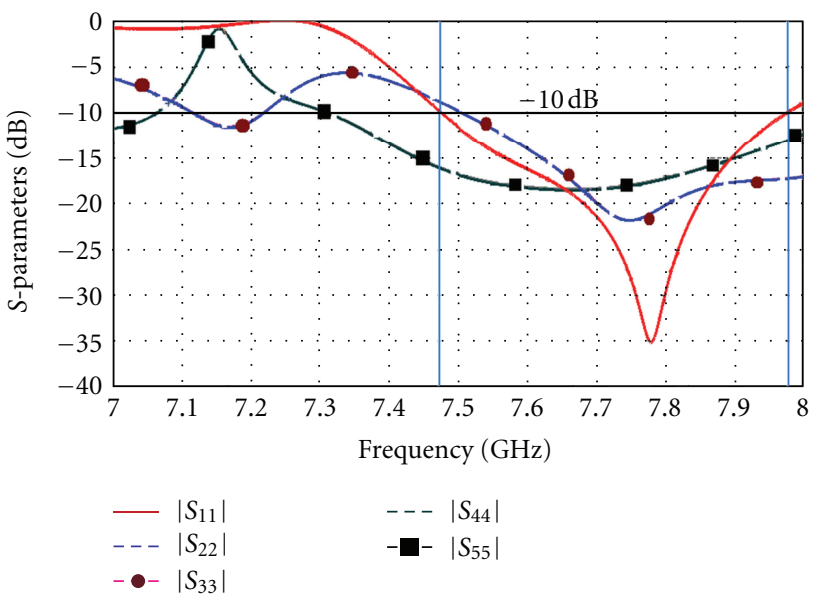

FIgURE 7: Reflection coefficient magnitudes of the modes $\mathrm{TE}_{11}$, $\mathrm{TM}_{01}$, and $\mathrm{TE}_{21}$ when the symmetric reflector is excited with a triple-mode feedhorn.

excitations, which is attributed to the higher order mode radiation behavior. However, comparing $\mathrm{TE}_{11}+\mathrm{TE}_{21}$ mode combination's radiation performance with that of the $\mathrm{TE}_{11}+$ $\mathrm{TM}_{01}$ based patterns, one can see that, the $\mathrm{TE}_{11}+\mathrm{TE}_{21}$ mode offers better gain and cross-polarization performance.

The reflector antenna radiation pattern performance, when the three modes are combined that is, $\mathrm{TE}_{11}(40 \%)+$ $\mathrm{TM}_{01}(30 \%)+\mathrm{TE}_{21}(30 \%)$ with fixed phase values of $+90^{\circ}$ and $-90^{\circ}$, are shown in Figures 10 (a) and $10(\mathrm{~b})$, respectively. Good copolarization gain of around $37 \mathrm{dBi}$ for $+90^{\circ}$ case is shown in Figure 9(a). Similarly, gain of $37 \mathrm{dBi}$ for the $-90^{\circ}$ case is shown in Figure 9(b). The combined mode shows more gain as input amplitude of $40 \%$ is used for the $\mathrm{TE}_{11}$ mode, which is the dominant mode for the feedhorn, and lower amplitudes of $30 \%$ each is fed to the other two modes, and hence, it results in the increased antenna gain, in addition to slightly reduced peak cross-polarization level.
TABle 1: Peak copolarization gain and peak cross-polarization level (below peak gain) values at $7.73 \mathrm{GHz}$ with the different mode combinations. The power to the individual mode is given in percentage.

\begin{tabular}{lcc}
\hline Mode Combination & $\begin{array}{c}\text { Peak Co-Pol } \\
\text { Gain [dBi] }\end{array}$ & $\begin{array}{c}\text { Peak } \\
\text { Cross-Pol } \\
\text { Level [dB] }\end{array}$ \\
\hline $\begin{array}{l}\mathrm{TE}_{11}(50 \%)+\mathrm{TM}_{01}(50 \%) \text { for } \\
+90^{\circ}\end{array}$ & 35.18 & -8.74 \\
$\mathrm{TE}_{11}(50 \%)+\mathrm{TE}_{21}(50 \%)$ for & 34.75 & -11.75 \\
$+90^{\circ}$ & & -15.2 \\
$\mathrm{TE}_{11}(40 \%)+\mathrm{TM}_{01}(30 \%)+$ & 37.13 & \\
$\mathrm{TE}_{21}(30 \%)$ for $+90^{\circ}$ & & \\
\hline
\end{tabular}

TABLE 2: Peak copolarization gain and peak cross-polarization levels (below peak gain) at $7.73 \mathrm{GHz}$ for $+90^{\circ}$ phase with different amplitude components.

\begin{tabular}{lcc}
\hline Mode Combination & $\begin{array}{c}\text { Peak Co-Pol } \\
\text { Gain [dBi] }\end{array}$ & $\begin{array}{c}\text { Peak } \\
\text { Cross-Pol } \\
\text { Level [dB] }\end{array}$ \\
\hline $\begin{array}{l}\mathrm{TE}_{11}(20 \%)+\mathrm{TM}_{01}(40 \%) \\
+\mathrm{TE}_{21}(40 \%)\end{array}$ & 36.34 & -10.25 \\
$\mathrm{TE}_{11}(40 \%)+\mathrm{TM}_{01}(30 \%)$ & 37.13 & -15.2 \\
$+\mathrm{TE}_{21}(30 \%)$ & & \\
$\mathrm{TE}_{11}(60 \%)+\mathrm{TM}_{01}(20 \%)$ & 37.47 & -22.04 \\
$+\mathrm{TE}_{21}(20 \%)$ & & \\
\hline
\end{tabular}

Table 1 summarizes the antenna performance for the three different combinations of modes for $+90^{\circ}$ phase value. It can be observed that, peak copolarization gain and peak cross-polarization level both improve by almost $3 \mathrm{~dB}$ with incorporation of all the three modes.

The variation of the peak copolarization and crosspolarization levels with the input mode combination of $\mathrm{TE}_{11}+\mathrm{TM}_{01}+\mathrm{TE}_{21}$ with mode amplitude distributions of $20 \%+40 \%+40 \%$ and $60 \%+20 \%+20 \%$ for a selected $+90^{\circ}$ phase at $7.73 \mathrm{GHz}$ are shown in Figures $11(\mathrm{a})$ and $11(\mathrm{~b})$, respectively. These triple-mode combination radiation performances are compared with $\mathrm{TE}_{11}(40 \%)+$ $\mathrm{TM}_{01}(30 \%)+\mathrm{TE}_{21}(30 \%)$ mode combination in Table 2 . An improvement in the peak cross-polarization level is observed whereas the antenna gain also increases when the $\mathrm{TE}_{11}$ mode has higher amplitude values than the $\mathrm{TM}_{01}$ and $\mathrm{TE}_{21}$ mode amplitudes.

\section{Offset Reflector Antenna Performance with Triple-Mode Feedhorn}

The symmetric reflector antenna fed by the triple-mode feedhorn showed reasonably good peak gain but high crosspolarization levels. An offset reflector antenna with the proposed feedhorn is now investigated to see the achievable impedance matching and radiation performances. The antenna geometry is shown in Figure 12. The reflector antenna has the same $f / D$ ratio of 0.50 with reflector diameter $D=1.2$ meter so that a comparison of this design 


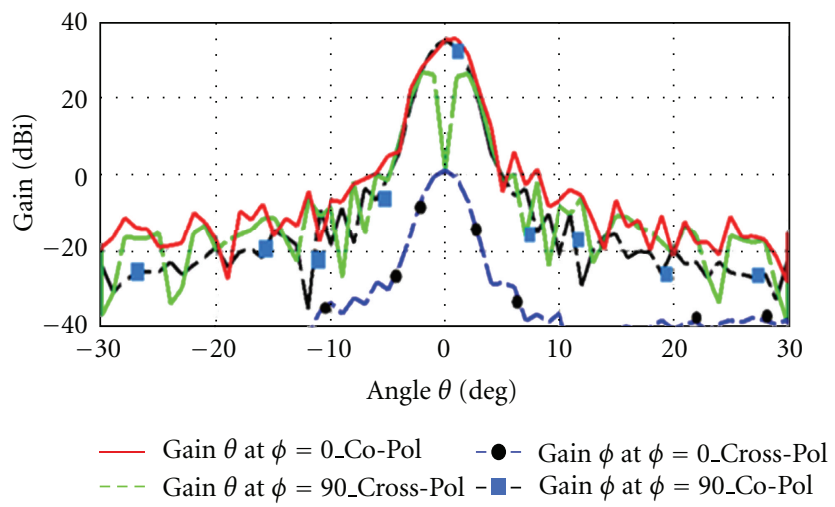

(a)

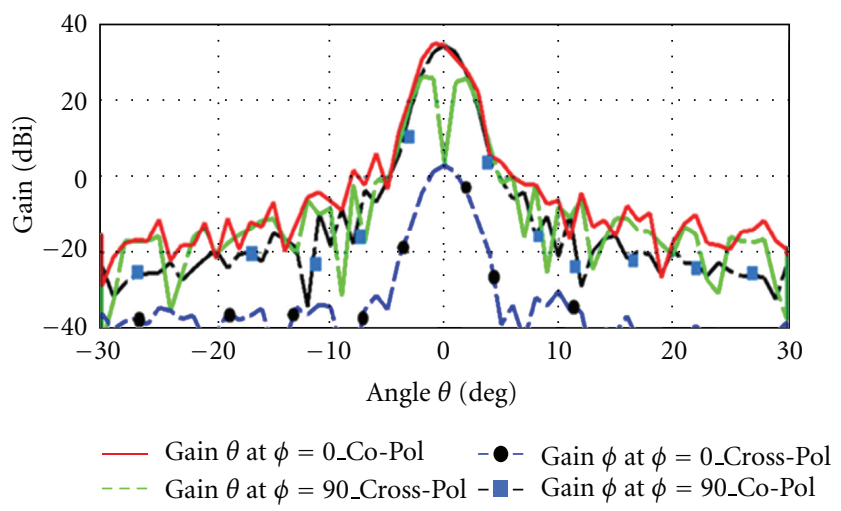

(b)

Figure 8: Reflector antenna radiation patterns at $7.73 \mathrm{GHz}$ with the feedhorn mode combination of $\mathrm{TE}_{11}(50 \%)+\mathrm{TM}_{01}(50 \%)$ for the fixed phase values of $(\mathrm{a})+90^{\circ}$ and $(\mathrm{b})-90^{\circ}$.

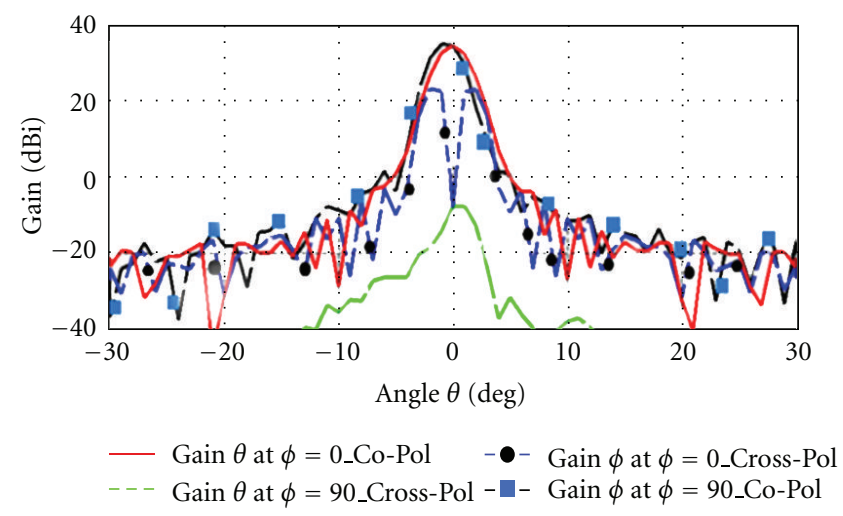

(a)

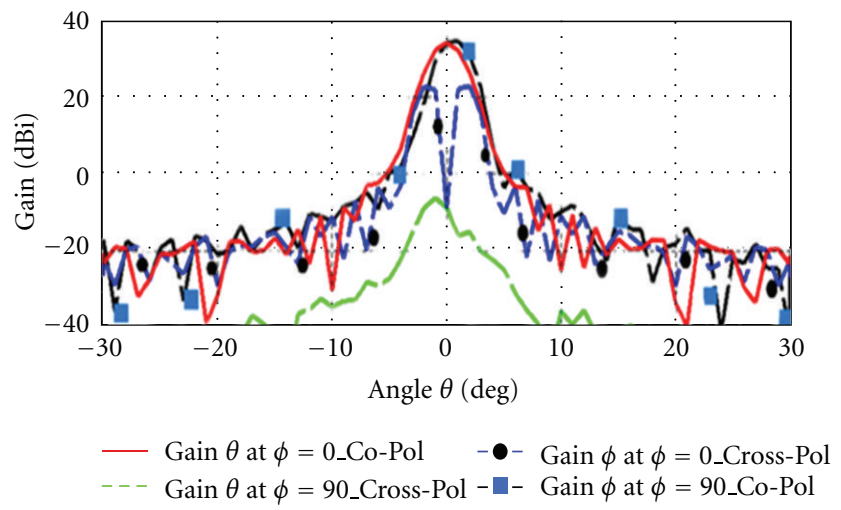

(b)

FIGURE 9: Reflector antenna radiation patterns at $7.73 \mathrm{GHz}$ with the feedhorn mode combination of $\mathrm{TE}_{11}(50 \%)+\mathrm{TE}_{21}(50 \%)$. Mode for the fixed phase values of $(\mathrm{a})+90^{\circ}$ and (b) $-90^{\circ}$.

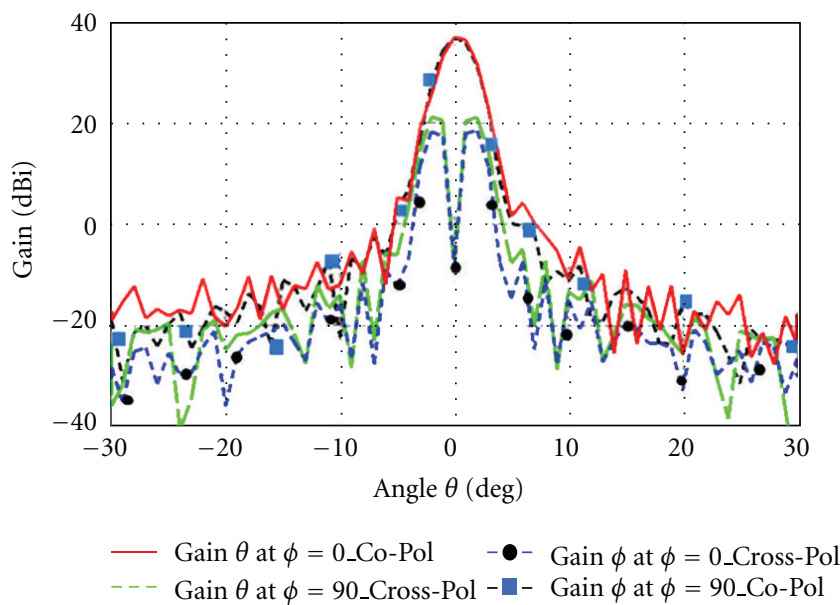

(a)

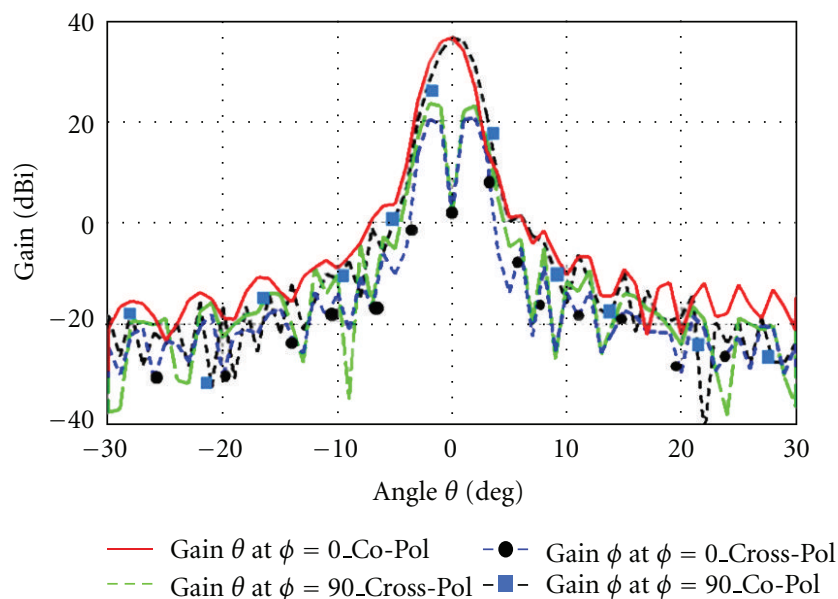

(b)

FIGURE 10: Reflector antenna radiation patterns at $7.73 \mathrm{GHz}$ with the feedhorn mode combination of $\mathrm{TE}_{11}(40 \%)+\mathrm{TM}_{01}(30 \%)+\mathrm{TE}_{21}(30 \%)$ for the fixed phase values of (a) $+90^{\circ}$ and (b) $-90^{\circ}$. 


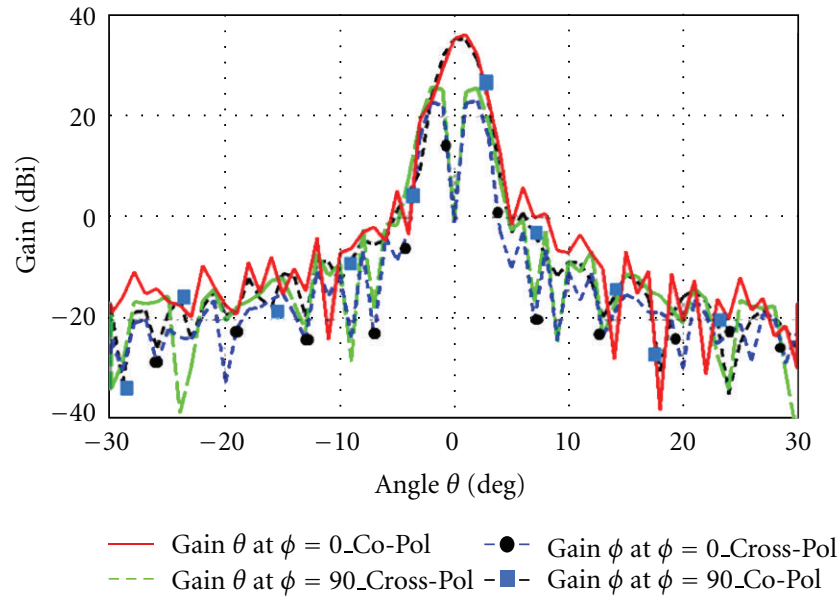

(a)

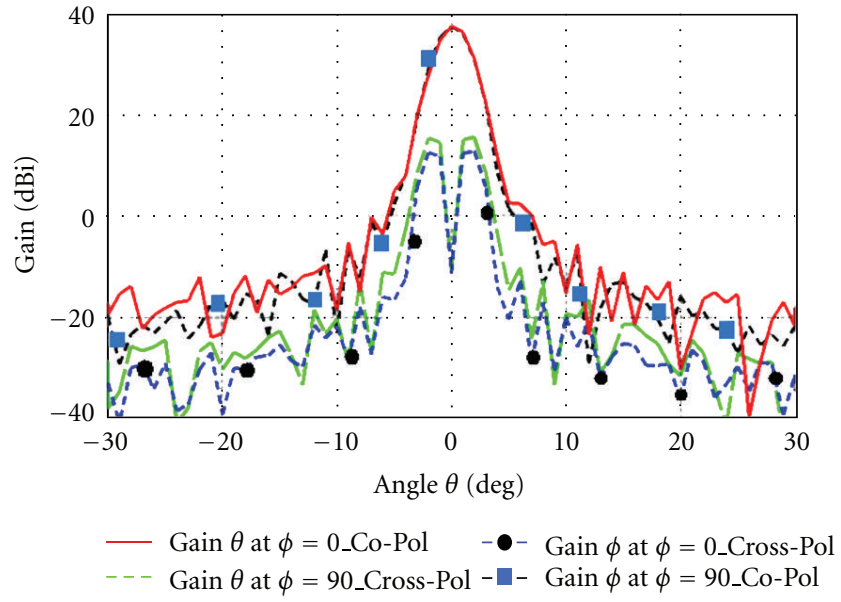

(b)

FIGURE 11: Reflector antenna radiation patterns at $7.73 \mathrm{GHz}$ with the feedhorn mode combination of $\mathrm{TE}_{11}+\mathrm{TM}_{01}+\mathrm{TE}_{21}$ for $+90^{\circ}$ phase with (a) $\mathrm{TE}_{11}(20 \%)+\mathrm{TM}_{01}(40 \%)+\mathrm{TE}_{21}(40 \%)$ and (b) $\mathrm{TE}_{11}(60 \%)+\mathrm{TM}_{01}(20 \%)+\mathrm{TE}_{21}(20 \%)$.

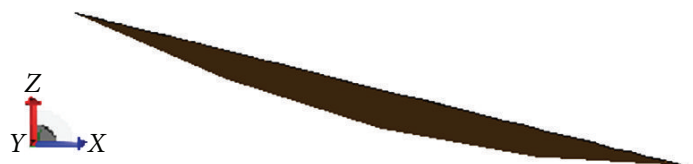

FIGURE 12: Configuration of the offset reflector antenna fed by a triple-mode feedhorn.

with that of the symmetric feedhorn reflector antenna can be made. The feed is placed at a tilt angle of $27.75^{\circ}$ with respect to that of the reflector surface which has been verified using the design equations in [10].

The reflection coefficient magnitudes for an offset reflector antenna are shown in Figure 13. The impedance matching bands obtained are similar to the matching bands obtained with the feedhorn alone and compares well with the symmetric reflector feedhorn combination also. Thus, impedance matching bandwidths are preserved. The $S_{11}$ corresponds to the reflection coefficient magnitude of the $\mathrm{TE}_{11}$ mode, whereas $S_{22}$ and $S_{33}$ correspond to the reflection coefficient magnitude of the $\mathrm{TM}_{01}$ mode. The $S_{44}$ and $S_{55}$ correspond to the reflection coefficient magnitude of the $\mathrm{TE}_{21}$ mode. The common matching bandwidths is from

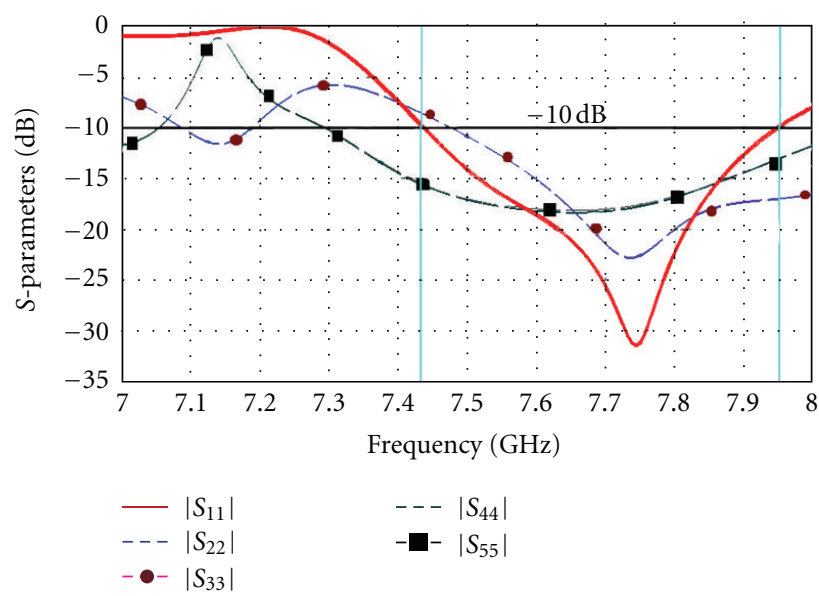

FiguRE 13: Reflection coefficient magnitude of the offset reflector antenna with triple-mode feedhorn.

7.44 to $7.96 \mathrm{GHz}$ with respect to the $S_{11}$ better than $-10 \mathrm{~dB}$ matching criteria.

The mode combination of $\mathrm{TE}_{11}(50 \%)+\mathrm{TM}_{01}(50 \%)$ with equal amplitude between the modes and a phase difference of $\pm 90^{\circ}$ applied between them is shown in Figure 14. The values for the peak gain copolarization and cross-polarization values are as specified in Table 3. Similar to the case of symmetric reflector antenna, the dual mode feedhorn excitations with an offset reflector also produce a beam scanning of $\pm 1^{\circ}$ for the $\pm 90^{\circ}$ phase shifts applied at the feedhorn ports. Once again, this beam squint is not because of the feed's scanned patterns or because of the phase center displacement. The peak copolarization to cross-polarization separations remain close to $-11.5 \mathrm{~dB}$ in Figure 14(a) and $-12.9 \mathrm{~dB}$ for case in Figure 14(b). 


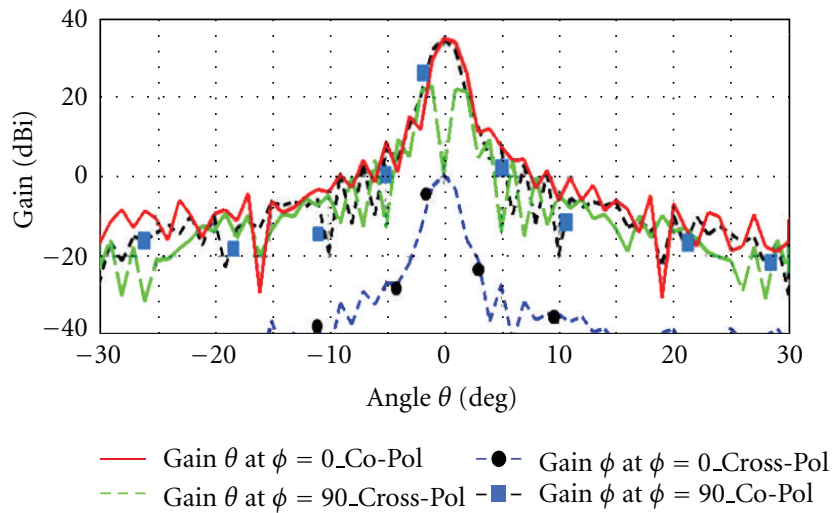

(a)

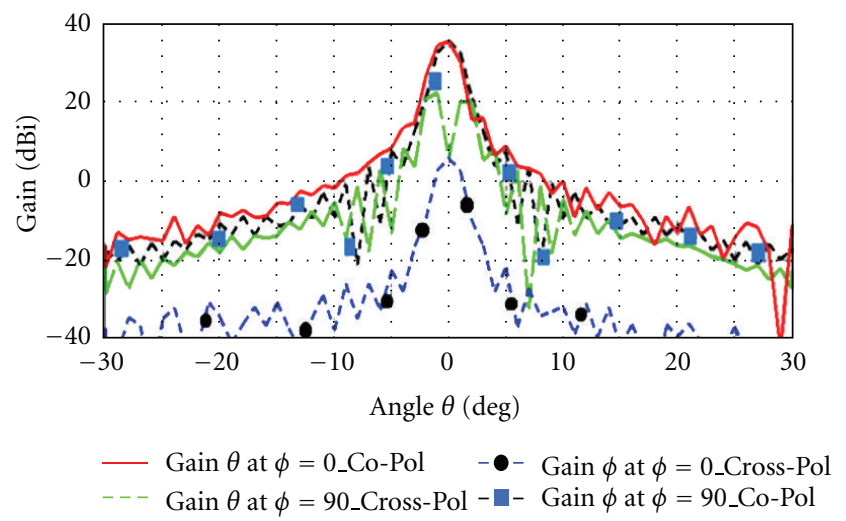

(b)

FIGURE 14: Reflector antenna radiation patterns at $7.73 \mathrm{GHz}$ with the feedhorn mode combination of $\mathrm{TE}_{11}(50 \%)+\mathrm{TM}_{01}(50 \%)$ for $(\mathrm{a})+90^{\circ}$ and (b) $-90^{\circ}$ phase values.

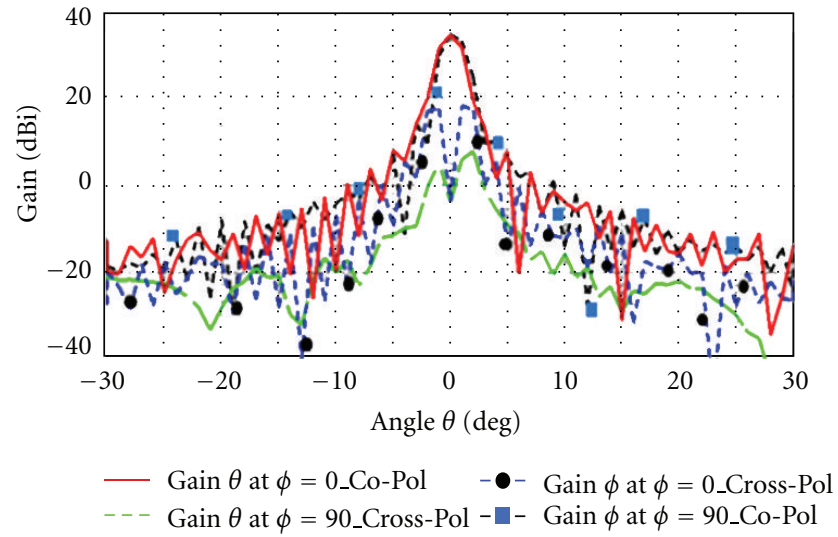

(a)

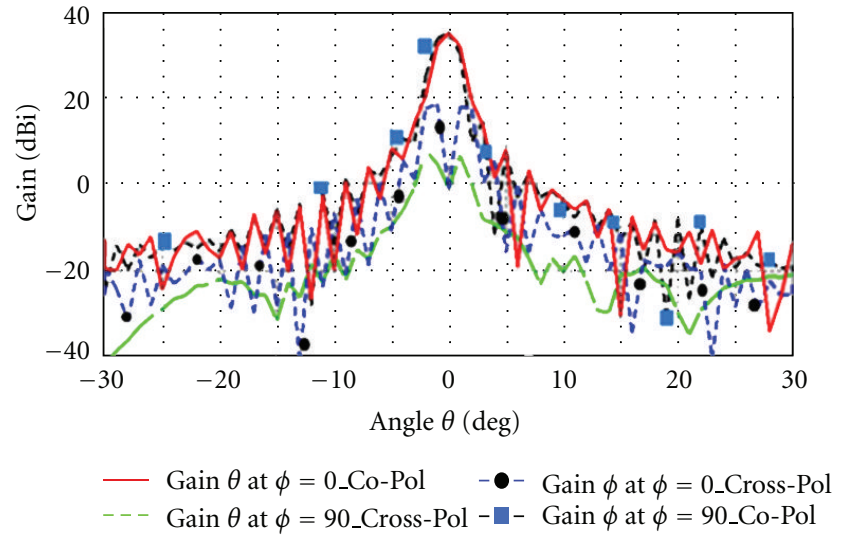

(b)

FIGURE 15: Reflector antenna radiation patterns at $7.73 \mathrm{GHz}$ with the feedhorn mode combination of $\mathrm{TE}_{11}(50 \%)+\mathrm{TE}_{21}(50 \%)$ for $(\mathrm{a})+90^{\circ}$ and (b) $-90^{\circ}$ phase values.

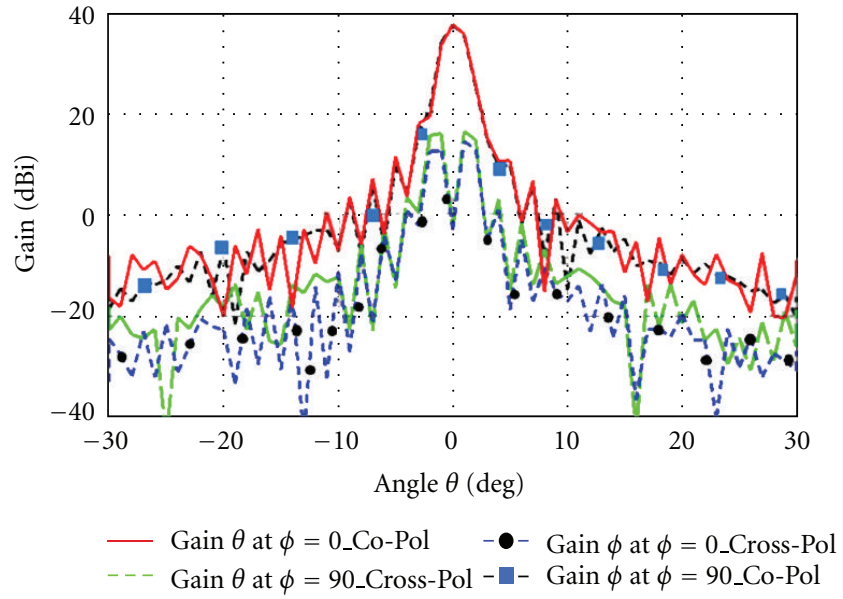

(a)

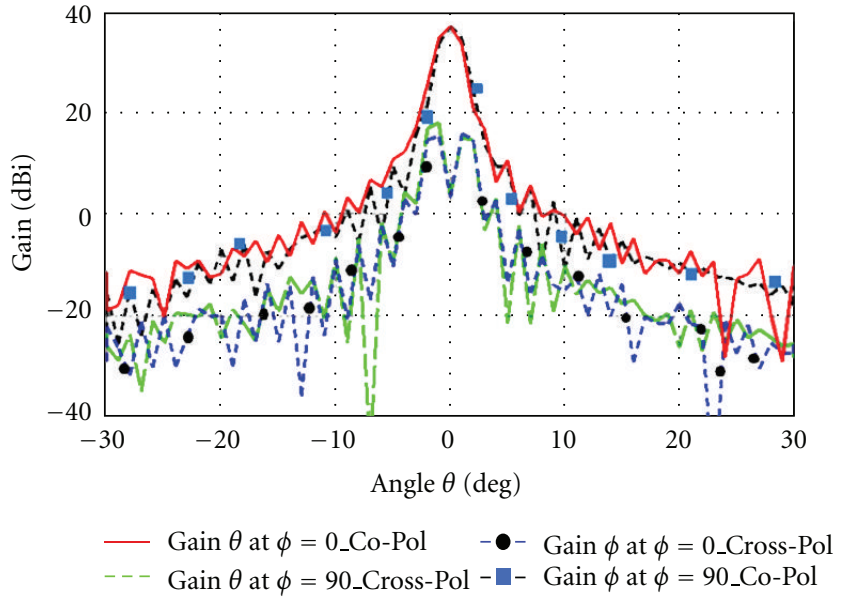

(b)

FIGURE 16: Reflector antenna radiation patterns at $7.73 \mathrm{GHz}$ with the feedhorn mode combination of $\mathrm{TE}_{11}(40 \%)+\mathrm{TM}_{01}(30 \%)+\mathrm{TE}_{21}(30 \%)$ for (a) $+90^{\circ}$ and (b) $-90^{\circ}$ phase values. 


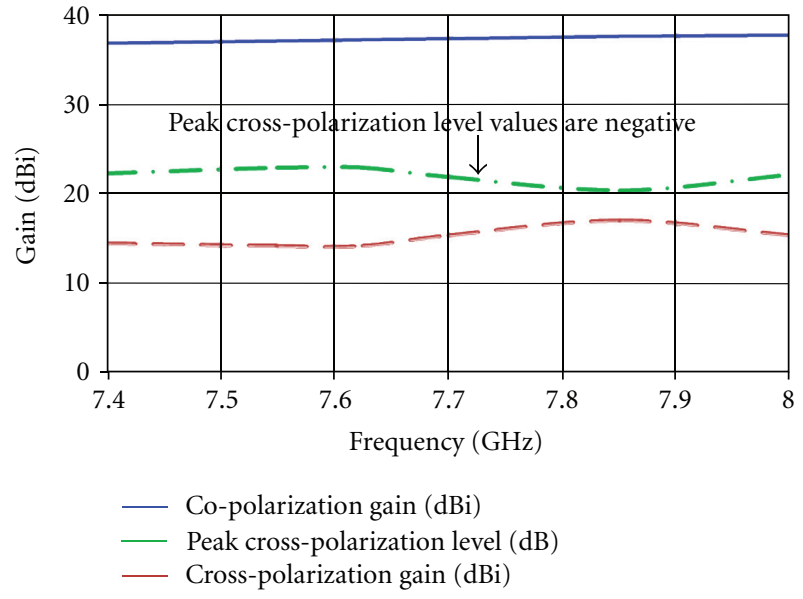

FIGURE 17: Representation of co- and cross-polarization Gain values along with peak cross-polarization level for the mode combination of $\mathrm{TE}_{11}(40 \%)+\mathrm{TM}_{01}(30 \%)+\mathrm{TE}_{21}(30 \%)$.

The reflector antenna radiation patterns with the mode combination of $\mathrm{TE}_{11}(50 \%)+\mathrm{TE}_{21}(50 \%)$ with equal amplitude distribution to the modes but with a phase difference of $\pm 90^{\circ}$ applied between them is shown in Figure 15. The values for the peak copolarization and cross-polarization gain values are as given in Table 3 . In this case, an increase in the cross-polarization levels is observed in both the $X Z$ and the $Y Z$ cut plane when compared to the previous case of symmetric reflector antenna. The peak co- and crosspolarization separations for the case shown in Figure 14(a) is $-16.1 \mathrm{~dB}$ and for Figure $14(\mathrm{~b})$, it is $-16.2 \mathrm{~dB}$ which indicates an improvement in the peak cross-polarization level compared to that of the symmetric reflector feedhorn antenna with the same mode combinations.

The gain radiation patterns for the mode combination of $\mathrm{TE}_{11}(40 \%)+\mathrm{TM}_{01}(30 \%)+\mathrm{TE}_{21}(30 \%)$ with phase values of $+90^{\circ}$ and $-90^{\circ}$ are shown in Figures 16(a) and 16(b), respectively. From Figure 16(a), we observe a copolarization gain of $37.28 \mathrm{dBi}$ and peak cross-polarization level of $-20.85 \mathrm{~dB}$. Similarly, Figure 15(b) shows a peak gain of $36.92 \mathrm{dBi}$ and peak cross-polarization level of $-19 \mathrm{~dB}$. When compared to the symmetric reflector antenna's peak cross-polarization levels of $-15 \mathrm{~dB}$ (Figure 10(a)) and $-13.2 \mathrm{~dB}$ (Figure 10(b)), an offset reflector antenna shows an improvement. Table 3 compares the copolarization gain and peak cross-polarization levels for the modes discussed above which confirms discussion of the radiation patterns presented above.

The copolarization gain, cross polarization gain and the peak cross-polarization separation levels over the common matching bandwidth of 7.44 to $7.96 \mathrm{GHz}$ is shown in Figure 17 for the mode combination of $\mathrm{TE}_{11}(40 \%)+$ $\mathrm{TM}_{01}(30 \%)+\mathrm{TE}_{21}(30 \%)$. It can be seen that the copolarization gain increases over the frequency band and is around $37 \mathrm{dBi}$. The peak cross-polarization gain is observed to be always better than $-21 \mathrm{~dB}$.

For comparison, the gain radiation patterns at $7.45 \mathrm{GHz}$ and $7.9 \mathrm{GHz}$ are also shown in Figures $18(\mathrm{a})$ and $18(\mathrm{~b})$,
TABLE 3: Peak copolarization gain and peak cross-polarization level (below peak gain) values at $7.73 \mathrm{GHz}$.

\begin{tabular}{lcc}
\hline Mode Combination & $\begin{array}{c}\text { Peak Co-Pol } \\
\text { Gain [dBi] }\end{array}$ & $\begin{array}{c}\text { Peak } \\
\text { Cross-Pol } \\
\text { Level [dB] }\end{array}$ \\
\hline $\begin{array}{l}\mathrm{TE}_{11}(50 \%)+\mathrm{TM}_{01}(50 \%) \\
\text { for }+90^{\circ}\end{array}$ & 34.94 & -11.54 \\
$\mathrm{TE}_{11}(50 \%)+\mathrm{TE}_{21}(50 \%)$ & 34.63 & -16.13 \\
for $+90^{\circ}$ & & -20.85 \\
$\mathrm{TE}_{11}(40 \%)+\mathrm{TM}_{01}(30 \%)$ & 37.28 & \\
$+\mathrm{TE}_{21}(30 \%)$ for $+90^{\circ}$ & & \\
\hline
\end{tabular}

TABLE 4: Copolarization gain and peak cross-polarization level (below peak gain) values within bandwidth for the selected mode combination.

\begin{tabular}{lcc}
\hline $\mathrm{TE}_{11}(40 \%)+\mathrm{TM}_{01}(30 \%)$ & $\begin{array}{c}\text { Peak Co-Pol } \\
\text { Gain }[\mathrm{dBi}]\end{array}$ & $\begin{array}{c}\text { Peak Cross-Pol } \\
\text { Level }[\mathrm{dB}]\end{array}$ \\
\hline $\mathrm{TE}_{21}(30 \%)$ for $+90^{\circ}$ & 37.07 & -22.6 \\
At $7.45 \mathrm{GHz}$ & 37.28 & -20.85 \\
At $7.73 \mathrm{GHz}$ & 37.62 & -20.84 \\
At $7.9 \mathrm{GHz}$ &
\end{tabular}

respectively, for the mode combination of $\mathrm{TE}_{11}(40 \%)+$ $\mathrm{TM}_{01}(30 \%)+\mathrm{TE}_{21}(30 \%)$ for the selected $+90^{\circ}$ phase. The values for the copolarization gain and peak crosspolarization level are shown in Table 4 at $7.45 \mathrm{GHz}, 7.73 \mathrm{GHz}$ and $7.90 \mathrm{GHz}$. It can be observed that over the bandwidth, peak copolarization gain and peak cross-polarization levels are around $37 \mathrm{dBi}$ and $-21 \mathrm{~dB}$, respectively, as noted earlier also. In future, the proposed feedhorn will be fabricated and experimentally verified for impedance matching and radiation performance. Reflector antenna performance will also be verified.

\section{Conclusion}

In this paper, a triple-mode feedhorn was employed as a source to the symmetric and offset reflector antennas. The feedhorn is capable of generating adaptive beams as in beam steering antenna by controlling amplitude of the modes with fixed phase values. These beam positions translate to a specific phase center locations. When this feed was employed with a symmetric reflector, it showed reasonable gain but with higher peak cross-polarization levels than with an offset reflector antenna of the same diameter. Impedance matching bandwidths with the reflector antennas remained the same as for the feedhorn alone. The mode combinations of $\mathrm{TE}_{11}+$ $\mathrm{TM}_{01}, \mathrm{TE}_{11}+\mathrm{TE}_{21}$ and $\mathrm{TE}_{11}+\mathrm{TM}_{01}+\mathrm{TE}_{21}$ were investigated and it was noted that the best antenna gain and peak crosspolarization performance can be achieved when all three modes are excited in the feedhorn, for both the symmetric and offset reflector antennas. Further, an offset reflector antenna when excited with all the three modes resulted in peak copolarization gain and peak cross-polarization level of around $37 \mathrm{dBi}$ and $-21 \mathrm{~dB}$, respectively, throughout the 


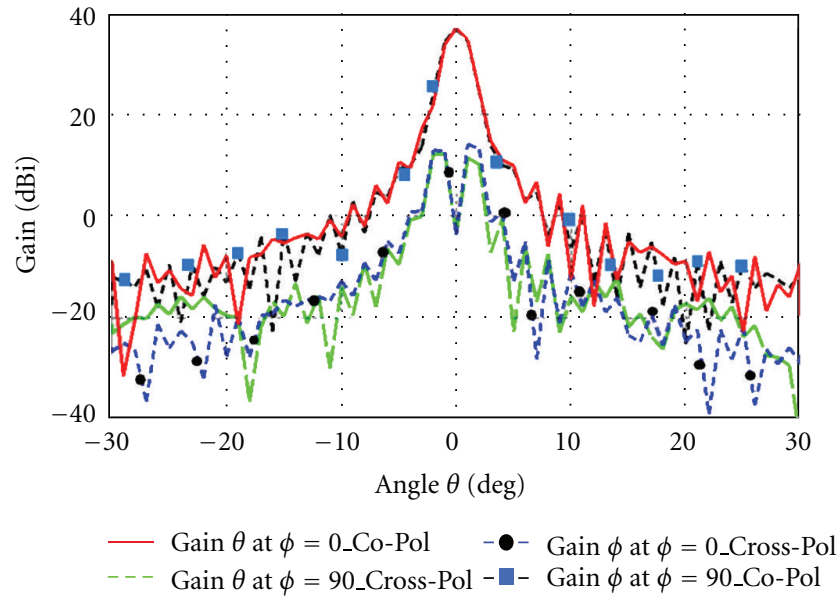

(a)

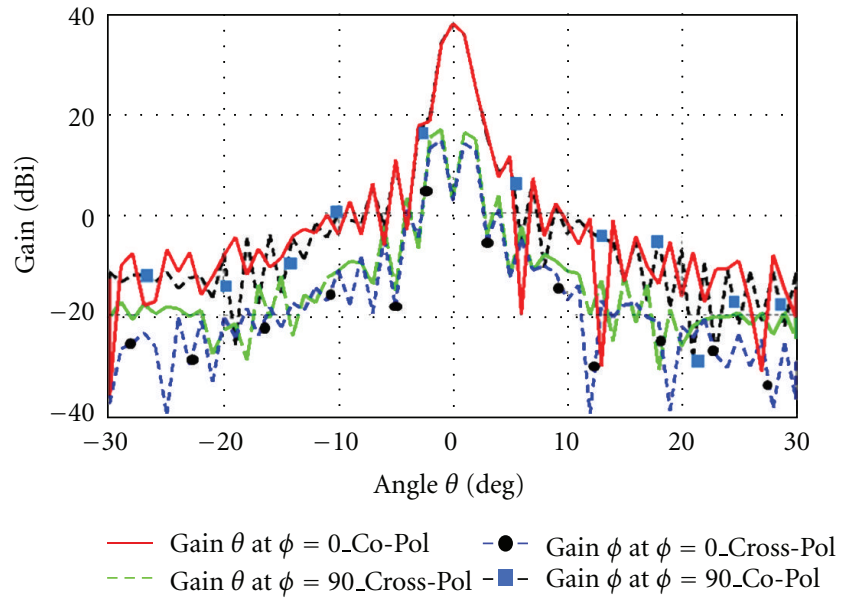

(b)

FIGURE 18: Reflector antenna radiation patterns with the feedhorn mode combination of $\mathrm{TE}_{11}(40 \%)+\mathrm{TM}_{01}(30 \%)+\mathrm{TE}_{21}(30 \%)$ with $+90^{\circ}$ phase for (a) $7.45 \mathrm{GHz}$, and (b) $7.9 \mathrm{GHz}$.

matching bandwidth. The investigated reflector antennas with the triple-mode feedhorn can find applications in GMTI and space-based radar applications.

\section{Acknowledgments}

The research work was supported with the National Science Foundation CAREER Grant no. ECCS-0845822. The authors also thank EMSS for providing FEKO license for performing this research work.

\section{References}

[1] J. Volakis, Antenna Engineering Handbook, McGraw-Hill, 4th edition, 2007.

[2] L. Shafai, S. K. Sharma, B. Balaji, A. Damini, and G. Haslam, "Multiple phase center performance of reflector antennas using a dual mode horn," IEEE Transactions on Antennas and Propagation, vol. 54, no. 11, pp. 3407-3417, 2006.

[3] B. Balaji, A. Damini, G. Haslam, L. Shafai, and S. Sharma, "Multiple Phase Center Feedhorn for Reflector Antennas," US Patent \# 7,180,459 granted February 20, 2007.

[4] L. Shafai and S. K. Sharma, "Performance of multimode $\left(\mathrm{TE}_{11}+\mathrm{TE}_{21}\right)$ feed horn for offset reflector antenna providing multiphase centres," in Proceedings of the IEEE Antennas and Propagation Society International Symposium and USNC/URSI Meeting (ANTEM '04), pp. 155-159, Ottawa, Canada, 2004.

[5] L. Shafa and S. K. Sharma, "A virtual array concept for reflector antenna aperture," in Proceedings of the International Symposium on Antennas and Propagation (ISAP'04), vol. 1, pp. 201-204, Sendai, Japan, August 2004.

[6] S. K. Sharma and A. Tuteja, "Investigations on a triple mode waveguide horn capable of providing scanned radiation patterns," in Proceedings of the IEEE International Symposium on Antennas and Propagation and CNC-USNC/URSI Radio Science Meeting (AP-S/URSI '10), pp. 1-4, July 2010.

[7] M. Thayagrajan and S. K. Sharma, "Some investigations on reflector antenna performance by employing a triple mode feedhorn using FEKO," in Proceedings of the 28th Annual Review of Progress in Applied Computational Electromagnetics Society (ACES '12), pp. 10-14, Columbus, Ohio, USA, April 2012.

[8] EMSS FEKO, http://www.emssusa.com/.

[9] D. M. Pozar, Microwave Engineering, John Wiley \& Sons, New York, NY, USA, 3rd edition.

[10] W. Stutzman and M. Terada, "Design of offset-parabolic reflector antennas for low cross-pol and low sidelobes," IEEE Antennas and Propagation Magazine, vol. 35, no. 6, pp. 46-49, 1993. 

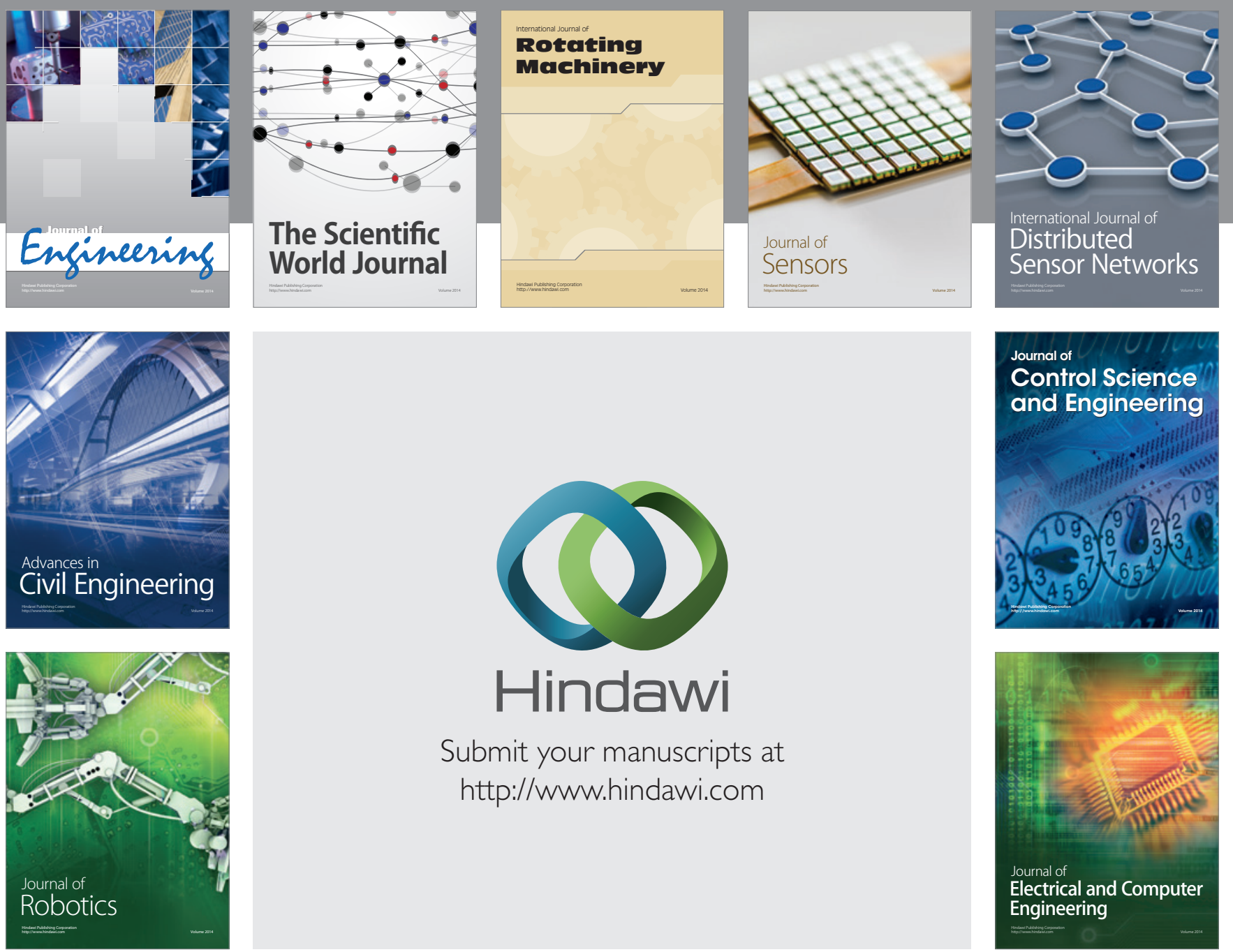

Submit your manuscripts at

http://www.hindawi.com
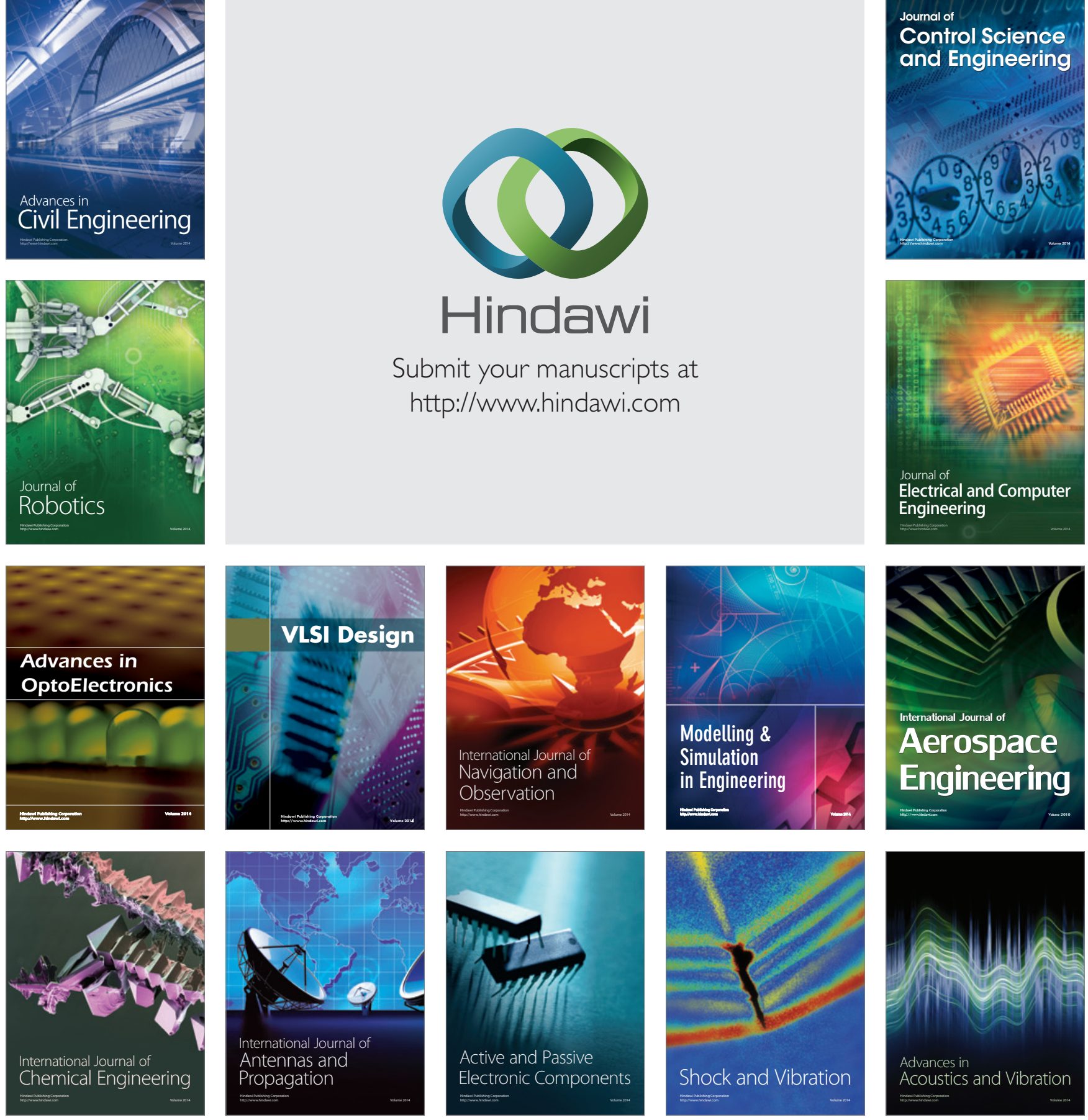